\title{
Arpa Ön Verim Denemesi Materyalinin Arpa Çizgili Yaprak Lekesi Hastalığına Karşı Reaksiyonlarının Belirlenmesi
}

\author{
Nilüfer AKCI $\dot{I}^{1} \quad$ Kadir AKAN $^{2} \quad$ İsmail SAYIM $^{1} \quad$ Namuk ERGUN $^{1} \quad$ Sinan AYDOĞAN $^{1}$ \\ ${ }^{1}$ Tarla Bitkileri Merkez Araştırma Enstitüsü Müdürlüğü, Ankara \\ ${ }^{2}$ Ahi Evran Üniversitesi Ziraat Fakültesi Bitki Koruma Bölümü, Kırşehir \\ $\triangle$ : nilufer.akci@tarim.gov.tr
}

Geliş (Received): 04.11.2017

Kabul (Accepted): 15.12.2017

\begin{abstract}
ÖZET: Arpa, buğdaygiller grubundan taneleri malt ve yem sanayisinde kullanılan önemli bir bitkidir. Orta Anadolu Bölgesi üretim alanlarında arpanın verim ve kalite özelliklerini olumsuz yönde etkileyen biyotik ve abiyotk stres faktörler bulunmaktadır. Arpa çizgili yaprak lekesi (etmen: Pyrenophora graminea (anamorph: Drechslera graminea)) hastalığı arpanın önemli fungal hastalıklarından birisidir. Hastalığın kontrolünde dayanıklı çeşitlerin kullanılması önerilmektedir. Bu çalışmanın amacı; Tarla Bitkileri Merkez Araştırma Enstitüsü (TARM) arpa 1slah birimince geliştirilen 1.523 arpa ön verim denemesi materyalinin arpa çizgili yaprak lekesi hastalığına karşı fide evresinde reaksiyonlarının belirlenmesidir. Çalışma 2016 yılında TARM Yenimahalle (Ankara) lokasyonu sera koşullarında yürütülmüştür. Materyale hastalığın inokulasyon için sandviç metodu ile kullanılmış olup çalışma, 2 tekerrürlü olarak yürütülmüştür. Ekimler $7 \pm 2 \mathrm{~cm}$ sıra arası mesafeye $20 \pm 1 \mathrm{~cm}$ 'lik siralara elle yapılmıştır. Hastalıklı bitkilerin toplam bitkiye oranlanması ile hastalık reaksiyonları belirlenmiştir. $\% 20$ ve daha düşük reaksiyon belirlenen materyal dayanıklı olarak değerlendirilmiştir. Hassas kontrol grubun da hastalıklı bitki oranı \% 70-100 olarak değerlendirilmiştir. Sonuçlar incelendiğinde; 1.362 arpa genotipinin (\% 89)'ü arpa çizgili yaprak lekesinin kullanılan izolatına karşı dayanıklı olduğu, 160 arpa genotipinin (\% 11) hassas olduğu belirlenmiştir. Çalışma sonucunda Islah grubundan gelen ön verim materyalinin hastalık reaksiyonları belirlenmiştir. Arpa 1slah programının sürdürülebilir bir şekilde sürekli gelişmesine katkı sağlanmıştır.
\end{abstract}

Anahtar Kelimeler: Arpa, arpa yaprak lekesi, reaksiyon testi, dayanıklılık ıslahı

\section{Reactions of Barley Genotypes in Preliminary Yield Trials to Leaf Stripe Disease}

ABSTRACT: Barley is an important plant of from grains used in the malt and feed industry. Some biotic and abiotic stress factors affect yield and quality characteristics in the unfavorable in Central Anatolia Plateau. Barley stripe leaf disease caused by Pyrenophora graminea (Anamorph: Drechslera graminea) is one of the important fungal diseases on barley. Resistant cultivars were recommended to cope with the disease. The goal of this study was to determine the reactions of 1.523 preliminary yield trials barley genotypes developed by the Central Research Institute for Field Crops (CRIFC) barley breeding unit.

The response of barley genotypes to barley stripe leaf disease was determined. The materials were infected by barley stripe leaf disease at seedling stage in greenhouse condition at CRIFC, in Yenimahalle (Ankara) in 2016. For disease inoculation, sandwich method was used and the study was conducted in two replications. Sowing was $20 \pm 1 \mathrm{~cm}$ line and distance between $7 \pm 2 \mathrm{~cm}$ rows by hand. Disease reactions were determined by the proportion of total plants to susceptible plants. The disease severity under $20 \%$ was considered to be resistant. The susceptible check infected $70-100 \%$ disease severity.

As a result; $1.362(89 \%)$ of the genotypes were determined as resistant, while 160 (11\%) genotypes were determined as susceptible. The disease of preliminary yield trials of the barley breeding program investigated. It has contributed to the continuous development of the barley breeding program in a sustainable way.

Key Words: Barley, barley leaf stripe, reaction test, genetic resistance

\section{GİRiș}

Gerek dünyada gerekse ülkemizde arpa üretim miktarının ve kalitesinin artırılması veya iyileştirilmesi önündeki engellerden birisi de, biyotik stres faktörlerinden olan fungal hastalıklardır. Hastalıklar görülme şiddeti ve oranına bağlı olarak ürünün verim ve kalitesini olumsuz yönde etkilemekte olup farklı düzeylerde ekonomik kayıplar oluşabilmektedir. Arpa çizgili yaprak lekesi hastalığı Pyrenophora graminea [anamorph: Drechslera graminea]' etmeni tarafindan oluşturulan yar1-biyotrof ve tohumla taşınan fungal bir hastalık olup arpa yetiştiricilik alanlarında arpa üretimini olumsuz yönde etkileyebilmektedir. Hastalık nedeniyle Orta Anadolu yetiştiricilik şartlarında farklı düzeylerde ekonomik kayıpların yaşandığ bilinmektedir. Hastalık ülkemizde ilk kez Bremer ve arkadaşları tarafından 1947 yılında İzmir ve Ankara'da belirlenmiştir (Tunalı, 1992). Çetinsoy (1995) tarafından yürütülen bir çalışmada hastalığının arpada hemen hemen her yıl \% 12 düzeyinde ürün kayıplarına neden olabildiği bildirilmiştir. Aktaş (1984) ise Türkiye'de arpa çizgili yaprak lekesi hastalığının neden olduğu ürün kaybının \% 10-15 arasında değiştiğini bildirmiştir. Orta Anadolu Bölgesi arpa üretimi yapılan 11 ilde 1984, 1987, 1988 yıllarında Damgacı ve Aktuna (1988) tarafından yapılan sürvey çalışmalarında 
sırasıyla 71, 21 ve 58 arpa tarlasında hastalıklı bitkilerin oranı $\% 4.7,5.5$ ve 4.2 olarak belirlenmiş ve ürün kayıpları sırasıyla \% $3.3,4.7$ ve 4.2 olduğu belirlenmiştir. Yine Tunalı (1992) tarafından Ankara ve çevresi arpa üretim alanlarında 1989, 1990 ve 1991 Yıllarında yürütülen bir sürvey çalışmasında hastalık şiddetinin sırasıyla \% 9.37, 2.32 ve 6.17 olduğu bildirilmiştir. Benzer şekilde Mamluk ve ark., (1997) tarafindan Orta Anadolu Bölgesi arpa üretim alanlarında 3 yıl süreyle yürütülen bir survey çalışmasında kontrol edilen alanların \% 50'den fazlasının etmen ile bulaşık olduğu ve $\% 10$ seviyesinde ürün kaybına neden olduğunu bildirmişlerdir.

Ülkemizde hastalığın kontrol edilmesi konusunda "Zirai Mücadele Teknik Talimatlarında" yeterli bilgi mevcuttur. Hastalığın kontrolünde hastalıktan ari ve sertifikalı tohumluk kullanılması veya üreticinin tohumluğunu tavsiye eden şekilde ilaçlaması önerilmektedir. Sertifikalı ve ilaçlanmış tohum kullanılması hastalığın kontrol altında tutulmasında etkili ve ekonomik bir yöntemdir. Farklı gerekçelerle üreticiler arasında son yıllarda sertifikalı tohumluk kullanım miktarı artmaktadır. Halen sınırlı düzeyde görülen hastalığın sertifikalı tohumluk kullanımının devam etmesi durumunda görülme sıklığının ve zararının ilerleyen yıllarda daha da azalması beklenilmektedir. Diğer taraftan tohum ilaçlamasının yapılamadığı veya yapılmadığı (organik üretim) durumlarda hastalığın kontrol altında tutulması için hastalığa dayanıklı çeşitlerin yetiştirilmesi tavsiye edilmektedir. Dayanıklı çeşit kullanılması için öncelikle hastalık reaksiyon testlerinin yapılması ve kabul edilebilir düzeyde dayanıklı olan genotiplerin tescil ettirilerek üretim de kullanılması teşvik edilmelidir.

Çetin ve ark., (1995) tarafindan yürütülen bir çalışmada; 1990 ve 1995 yılları arasında 5 üretim sezonunda hastalığa karşı bazı arpa materyalinin reaksiyonları belirlemişlerdir. Çalışma sonucunda Haymana (İkizce) izolatına karşı çoğu Türk arpa genotiplerinin hastalığa karşı hassas reaksiyon gösterdiğini bildirmişlerdir. Benzer şekilde Albustan ve ark., (1999) tarafindan 1998 yılı yürütülen bir çalışmada; arpa ıslah materyali geliştirme programı çerçevesinde arpa çizgili yaprak lekesi ve arpa yaprak lekesi hastalıklarına karşı çoklu dayanıklı reaksiyon gösteren genotiplerin geliştirilmesini amaçlandıkları çalışmalarında 1.216 genotipden 33 genotipin her iki hastalığa da dayanıklı olduğunu bildirmişlerdir.

Ulus (2006) 15 arpa çeşidinin, Ankara lokasyonun farklı alanlarından toplanmış 5 farklı izolatına karşı reaksiyonlarını sera koşullarında belirlemiştir. Çalışma sonucunda; Yerçil ve Çumra 2001 çeşitlerinin 5 izolata karşı dayanıklı reaksiyon gösterdiği, Erginel 90, Orza 96, Çetin 2000 ve Aydanhanım çeşitlerinin 3 izolata karşı hassas reaksiyon gösterdiğini bildirmiştir. Benzer şekilde Bayraktar ve Akan (2012) tarafından yürütülen bir çalışmada ise; 13 farklı patojenik izolatın 48 arpa çeşidi üzerinde reaksiyonlarını belirlemişlerdir. Çalışma sonucunda Durusu, Balkan 96 (Igri), Çumra 2001 ve Anadolu 98 çeşitlerinin tüm izolatlara karşı dayanıklı reaksiyon gösterdiğini belirlemişlerdir. Akan ve ark., (2016), Tarla Bitkileri Merkez Araştırma Enstitüsü (TARM) Arpa Islah Birimince geliştirilen 95 arpa genotipinin sera şartlarında 2 farklı hastalık izolatına karşı gösterdiği reaksiyonları değerlendirmişlerdir. Çalışma sonucunda 1. Izolata karşı 34 (\% 36) genotipin dayanıklı, 2. Izolata karşı ise 15 (\%16) genotipin dayanıklı olduğunu bildirmişlerdir.

$\mathrm{Bu}$ araştırmanın amacı; Tarla Bitkileri Merkez Araştırma Enstitüsü (TARM) arpa 1slahı birimi tarafindan farklı amaçları olan arpa 1slah programları için geliştirilmiş ön verim denemesinde bulunan 1.523 genotipden oluşan materyalin arpa çizgili yaprak lekesi hastalığına karşı sera şartlarında fide evresinde reaksiyonlarının belirlenmesidir. Entegre yaklaşımlarla yönetilmesi gereken 1slah programlarında materyalin verim, verim öğeleri ile agronomik özelliklerinin belirlenmesinin yanı sıra hastalık reaksiyonlarının bilinmesi hem çeşit geliştirme çabaları hem de hastalığın kontrolü için oldukça önemlidir.

\section{MATERYAL ve YÖNTEM}

Çalışma materyali Tarla Bitkileri Merkez Araştırma Enstitüsü (TARM) arpa 1slahı birimi tarafindan farklı amaçları olan programlar için geliştirilmiş olup ön verim denemesinde bulunan 1.523 genotipden oluşmaktadır. Çalışma, Tarla Bitkileri Merkez Araştırma Enstitüsü Ankara-Yenimahalle lokasyonunda bulunan seralarında yürütülmüştür.

Hastalığın ilk inokulum kaynağı olan enfekteli yapraklar küçük parçacıklara ayrılmıştır. Bu parçalar \% 70'lik etil alkolde 10 saniye, sonrasinda \% 5, lik sodyum hipoklorit ( $\mathrm{NaClO}$ ) içerisinde 90 saniye tutularak yüzey sterilizasyonu sağlanmıştır. Hastalık etmeni PDA (Patoto Dextroz Agar) ortamında çoğaltılmış olup PDA ortamına alınan etmen $20 \pm 2{ }^{\circ} \mathrm{C}$ de sicaklıkta 12-14 gün süreyle koloni oluşumu sağlanıncaya kadar tutulmuştur (Albustan ve ark., 1999). Hastalığın tohuma inokulasyonun da sandviç metodu kullanılmıştır. Her bir genotip gelişmiş olan fungus kültürünün üzerine $14 \pm 2$ adet tohum olacak şekilde konulmuş ve diğer kısmı eş büyüklükteki hastalık kültürüyle kapatılmıştır. Arasında tohum bulunan kültür içeren petriler 72 saat süreyle $22 \pm 2$ ${ }^{\circ} \mathrm{C}$ 'de 1 şık altında tutulduktan sonra genotiplerin çimlenme özellikleri dikkate alınarak 5-7 gün arasında +4 ${ }^{\circ} \mathrm{C}$ sicaklıkta tutularak hastalığın inkubasyonu sağlanmıştır (Mohammad and Mahmood 1974). İnkubasyon süresi sonunda tohumlar sandviç ortamlarından dikkatlice alınarak kum, hayvan gübresi, toprak karışımı bulunan yastıklara 2 tekerrürlü olacak ekilmiştir. Ekimler Kasım ayı başı ile Şubat ayı başı arasında yapılmıştır. Ekimler $7 \pm 2 \mathrm{~cm}$ sıra arası mesafeye $20 \pm 1 \mathrm{~cm}$ 'lik sıralara elle yapılmıştır. Materyal gece-gündüz sıcaklığı $10-22{ }^{\circ} \mathrm{C}$ arasında değişen sera koşullarında uygun bakım işlemleri yapılarak yetiştirilmiştir. Her 10 materyalden sonra ekimi yapılan hassas kontrol (Atılır) genotipi de materyalle birlikte aynı zamanda, aynı şekilde inokule edilmiş ve 
ekilmiştir. Bitkilerde düzenli bir çıkış sağlanmış olup bitkiler gerektikçe sulanmıştır.

Hastalığın değerlendirilmesi ekimden $60 \pm 2$ gün sonra her bir genotipin sağlam ve hastalıklı bitkileri sayılarak yapılmıştır. Hassas bitkilerin toplam bitkiye oranlanması ile hastalık reaksiyonları belirlenmiştir. Sonuçların değerlendirmesinde bir genotipe ait iki tekerrürden yüksek olan $\%$ hastalık oranı skoru dikkate alınmıştır. Çalışma da, Tekauz tarafindan geliştirilen skalanın Bayraktar ve Akan (2012) tarafindan modifiye edilerek geliştirilen gruplandırması kullanılmıştır. Bu gruplandırmaya göre Immun (I): \% 0; dayanıklı (R): \% 1-5; orta dayanıklı (MR): \% 6-20; orta hassas (MS): \% 21-30; hassas (S): \% 31-70; çok hassas (VS): \% 71-100) olarak bildirilmiştir. \% 20 ve daha düşük reaksiyon gösteren materyal dayanıklı olarak değerlendirilmiştir.

\section{BULGULAR ve TARTIŞMA}

Her 10 sıradan sonra bir olacak şekilde ekilen hassas kontrol genotipinde (Atılır) hastalık \% 70-100 oranında belirlenmiştir. Hassas kontrol genotipi üzerinde yapılan bu değerlendirme sonucunda "test materyalinde reaksiyon testlerinin sonuçlarının güvenilir" olduğu yorumu yapılmış ve test materyali değerlendirilmiştir. Test materyalinin hastalığa reaksiyonlarının enfeksiyon gruplarına göre dağılımı, hastalıklı bitki oranının \% olarak göre dağılımı, dayanıklı ve hassas olarak belirlenen genotip sayıları ve \%'leri Çizelge 1' de verilmiştir.

Islah çalışmaları uzun süren ve sabır gerektiren çalışmalardır. Çalışma materyaline kısmen benzer bir materyal ile, Çetin ve ark., (1995) tarafindan 1990 ve 1995 yılları arasında 5 üretim sezonunda yürütülen bir çalışma sonucunda Türk arpa genotiplerinin çoğunun arpa çizgili hastalığına karşı hassas olduğunu bildirilmişlerdir. Aynı lokasyondan alınan farklı izolatla yaklaşık 20 yıl sonra yapılan çalışmada ön verim kademesinde bile kabul edilebilir düzeyde dayanıklılık oranının \% 89'a ulaştığ 1 belirlenmiştir. Bu durum dayanıklı materyal geliştirilmesinde melez bahçesi materyalinden başlanarak materyal üzerinde sistemli bir çalışma sonrasında hedefe ulaşılabileceğinin açık göstergesi olarak düşünülmektedir.

Çizelge 1. Test materyalinin hastalığa reaksiyonlarının enfeksiyon gruplarına göre dağılımı, hastalıklı bitki oranının \% olarak dağılımı, dayanıklı ve hassas olarak belirlenen genotip sayıları ve \%'leri

\begin{tabular}{lccccccc}
\hline \multicolumn{7}{c}{ Test edilen materyallerin enfeksiyon gruplarına göre dağılımı } \\
\hline Enfeksiyon grubu & 0 & $1-5$ & $6-20$ & $21-30$ & $31+$ & Diğer* & Toplam \\
\hline Materyal sayısı & 987 & 39 & 336 & 69 & 91 & 1 & 1.523 \\
\hline \multicolumn{8}{c}{ Hastalıklı bitki yüzdelerine (\%) göre dağılımı } \\
\hline Materyal oranı (\%) & 65 & 3 & 22 & 5 & 6 & 0 & 100 \\
\hline
\end{tabular}

Dayanıklı ve orta dayanıklı olarak belirlenen materyallerin sayıları ve \%'leri (\%20 ve altında olanlar)

\begin{tabular}{|c|c|c|c|c|}
\hline \multicolumn{2}{|c|}{ Dayanıklı ve Orta Dayanıklı } & \multicolumn{2}{|c|}{ Orta Hassas ve Hassas } & \\
\hline Materyal sayıs & Materyal oranı $(\%)$ & Materyal sayıs1 & Materyal oranı $(\%)$ & \\
\hline 1.362 & 89 & 160 & 11 & 1.523 \\
\hline
\end{tabular}

Diğer*: Değerlendirmesi mümkün olamayan materyal sayısı.

Diğer taraftan Ulus (2006), Bayraktar ve Akan (2012) ve Akan ve ark., (2016) tarafindan yürütülen ve farklı izolatların kullanıldığı çalışmalarda kabul edilebilir düzeyde dayanıklılık sınırlı düzeydedir. $\mathrm{Bu}$ çalışmaların 1şı̆̆ın da Arpa Islah Grubu tarafindan "Verim Denemesi" kademesine aktarılan materyalin mutlaka farklı izolatlara karşı test edilmesi gereklidir. $\mathrm{Bu}$ şekilde hem bölgede bulunan yaygın patotiplere karşı hem de etmenin zaman içerisinde yeni urklar oluşturabileceği varsayımıyla materyal geliştirilmesi gereklidir.

\section{SONUÇ}

Ön verim denemesinde bulunan arpa materyalinin arpa çizgili yaprak hastalığına karşı reaksiyonları belirlenerek kabul edilebilir düzeyde dayanıklı olarak belirlenen genotiplerin seçimi ile seleksiyon çalışmalarına katkı sağlanmıştır. Çalışmayla; sürdürülebilir tarımsal bir yaklaşımla, çevre koruma konularına hassas ve üretici/tüketici isteklerine uygun, arpa çizgili yaprak lekesi hastalığına dayanıklı materyal geliştirilmesi amaçlanmıştır. Entegre ürün yönetimi çerçevesinde hedef, ıslah strateji ve uygulamaları ile süreklilik sağlanması mümkün olabilecektir. Ek olarak Orta Anadolu Bölgesi için arpa üretim, verim ve kalitesinin sürdürülebilir bir şekilde iyileştirilmesi ve artırılmasıyla birlikte bunun doğal bir sonucu olarak üretici gelirleri artırılarak ülke ekonomisine katkı sağlanmış olacaktır.

\section{TEŞEKKÜR}

Çalışma Tarımsal Araştırmalar ve Politikalar Genel Müdürlüğünce finanse edilmiş ve desteklenmiştir (Proje No: TAGEM /TBAD/ 14/ A12/P01/002).

\section{KAYNAKLAR}

Akan K, Mert Z, Ergun N 2016. Arpa Ön Verim Denemesi Materyalinin Arpa Çizgili Yaprak Lekesine Karşı Reaksiyonlarının Belirlenmesi. Uluslararası Katılımlı Türkiye VI. Bitki Koruma Kongresi, 5-8 Eylül 2016, Konya Sayfa: 721 
Aktas H 1984. Spread of Leaf Spots in Barley Growing Areas in Turkey. Proc. $6^{\text {th }}$. Congr. Un. Phytopath. Mediterr. Cairo, Egypt. 338-341.

Albustan S, Çetin L, Düşünceli F, Tosun H, Akar T 1999. Orta Anadolu Bölgesi için TARM Tarafindan Oluşturulan 1998 Y1lı Arpa Nörserilerinde Yaprak Lekesi (Rhynchosporium secalis) ve arpa çizgili yaprak lekesi (Pyrenophora graminea) Hastalıklarına Karşı Dayanıklılık Bakımından Değerlendirilmesi. Orta Anadolu'da Hububat Tarımının Sorunları ve Çözüm Yolları Sempozyumu Bildirileri, 8-11 Haziran 1999 Konya; s:700-704.

Bayraktar H, Akan K 2012. Genetic Characterization of Pyrenophora graminea Isolates and the Reactions of Some Barley Cultivars to Leaf Stripe Disease Under Greenhouse Conditions. Turk J Agric For 36:329339.

Çetin L, Albustan S, Düşünceli F, Tosun H, Ottekin A, Akar T 1995. Bazı Arpa İleri Kademe Hat ve Çeşitlerinin İç Anadolu Bölgesinde Arpa Çizgili Yaprak Lekesi (Drechslera graminea) Reaksiyonları ve Verimle İlişkilerinin Belirlenmesi. Arpa-Malt Sempozyumu (III), 5-7 Eylül 1995, Konya.

Çetinsoy S 1995. Importance and Control of Barley Leaf Blight in Turkey. Rachis,14(1/2):25-26.
Damgac1 E, Aktuna İ 1988. The Investigations on the Establishment of Damage Degree and the Distribution of Barley Stripe (Pyrenophora graminea Ito \& Kurib.) in Central Anatolia and the Reactions of Some Barley Varieties against the Disease. The Journal of Turkish Phytopathology, 17: 116.

Mamluk OF, Çetin L, Brawn HJ et al., 1997. Current Status of Wheat and Barley Diseases in the Central Anatolian Plateau of Turkey, Phytopath. Medit, 36:167-181.

Mohammad A, Mahmood M 1974. Inoculation Techniques in Helminthosporium Stripe of Barley. Plant Disease Reporter, 58(1): 32-34.

Tunalı B 1992. Ankara İlinde Arpa Çizgi Hastalığ Etmeni Drechslera graminea (Rabh.) Shoem.'e Karşı Arpa Çeşitlerinin Dayanıklılıkları Üzerinde Araştırmalar. Ankara Üniversitesi Fen Bilimleri Enstitüsü Bitki Koruma Ana Bilim Dalı. 109 s.

Ulus C 2006. Bazı Arpa Çeşitlerinin Arpa Çizgili Yaprak Lekesi Hastalığı Etmeni Drechslera graminea (Rab.) Shoem. 'ya Karşı Reaksiyonlarının Belirlenmesi Ankara Üniversitesi Fen Bilimleri Enstitüsü Bitki Koruma Ana Bilim Dalı. 36 s. 